\title{
TRANSFORMING 2D CADASTRAL DATA INTO A DYNAMIC SMART 3D MODEL
}

\author{
E. Tsiliakou,*, T. Labropoulos, E. Dimopoulou
}

\begin{abstract}
School of Rural and Surveying Engineering, National Technical University of Athens, 9, Iroon Polytechneiou, 15780 Zografou, Greece - * eva.tsiliakos@gmail.com - (taslab, efi)@survey.ntua.gr
\end{abstract}

\author{
Commission II, WG II/2
}

KEY WORDS: 3D Cadastre, Hellenic Cadastre Project, 3D RRRs, Procedural Modeling, 3D GIS, Esri CityEngine

\begin{abstract}
:
3D property registration has become an imperative need in order to optimally reflect all complex cases of the multilayer reality of property rights and restrictions, revealing their vertical component. This paper refers to the potentials and multiple applications of $3 \mathrm{D}$ cadastral systems and explores the current state-of-the art, especially the available software with which $3 \mathrm{D}$ visualization can be achieved. Within this context, the Hellenic Cadastre's current state is investigated, in particular its data modeling frame. Presenting the methodologies and specifications addressing the registration of 3D properties, the operating cadastral system's shortcomings and merits are pointed out. Nonetheless, current technological advances as well as the availability of sophisticated software packages (proprietary or open source) call for 3D modeling.

In order to register and visualize the complex reality in 3D, Esri's CityEngine modeling software has been used, which is specialized in the generation of 3D urban environments, transforming 2D GIS Data into Smart 3D City Models. The application of the 3D model concerns the Campus of the National Technical University of Athens, in which a complex ownership status is established along with approved special zoning regulations. The 3D model was built using different parameters based on input data, derived from cadastral and urban planning datasets, as well as legal documents and architectural plans. The process resulted in a final 3D model, optimally describing the cadastral situation and built environment and proved to be a good practice example of 3D visualization.
\end{abstract}

\section{INTRODUCTION}

Contemporary urban environments are distinguished by their structural complexity and the multiple use of space in which a range of different RRRs (Rights, Restrictions and Responsibilities) intersect with the corresponding land parcels. Although cadastral registration is essential in order to secure rights, current 2D cadastral models do not adequately portray or manage the layered distribution of 3D RRRs. That is, 2D land parcels are not flexible enough to accommodate an increasing number of non-parcel based interests (Bennett et al. 2008; Kalantari et al, 2008). This range of land rights, restrictions and responsibilities requires proper $3 \mathrm{D}$ registrations complying with each legal structure, as well as systematic encoding and modelling, fully exploiting technical capabilities of 3D representations (Dimopoulou and Elia, 2012).

After all, according to Aien et al (2011) the 3D Cadastral Data Model should not only accommodate 3D RRRs and their association with physical objects; the data model should represent the spatial extent of 3D RRRs.

So far no country has developed a substantial 3D cadastral model, but some have resolved key issues concerning 3D registration or representation of $3 \mathrm{D}$ cases even in a $2 \mathrm{D}$ manner. The preliminary analysis of the survey conducted by the FIG joint commission 3 and 7 working group on 3D-Cadastres clarified the existing cadastral status of the countries that participated in this survey through a questionnaire. According to Stoter et al (2011) the first conclusion reached was that the concepts "3D Cadastre" and "3D parcels" are still ambiguous, due to cultural and historical differences which influence the organizational, technical and legal aspects of land registration. Most countries consider and treat solely apartment units as $3 \mathrm{D}$ parcels, within their cadastral system. The Hellenic Cadastre project treats only Special Real Property Objects (S.R.P.O.s) and natural resources (mining rights) as $3 \mathrm{D}$ objects (mines have spatial representation in distinct thematic polygon layers, under specific legislation).

3D RRRs such as condominium rights can be registered in all jurisdictions (with the exception of Poland and Nepal) but it is also possible to create rights limited in the third dimension, such as rights in empty spaces. Empty spaces, which may vary from air spaces to subsurface volumes are only registered in Australia and Canada (Quebec) or Finland (restricted to subsurface parcels), in contrast with most jurisdictions who merely hold regulations regarding the future constructions' rights or building permits, for example Norway. Finally, infrastructures such as cable and pipeline networks characterized by their 3D manner are only registered in limited cases. Among the countries introducing the registration of cable and pipeline networks accompanied with a cadastral number are the Netherlands and Switzerland. In Greece networks are recorded and managed by the responsible (private or state) organization.

$3 \mathrm{D}$ right objects are not registered in the cadastral database in most jurisdictions, while in others this information is separately kept in special registries or are spatially indexed in relation to the associated surface parcel via a $2 \mathrm{D}$ polygon in a single layer (Dimopoulou and Elia, 2012), e.g. in Australia, Croatia, Norway, Cyprus and Sweden. 3D registration is actually a resolved matter in Spain, where a 3D building model exists on the cadastral map, clarifying the allocation of rights inside the buildings.

It is quite evident that no jurisdiction has fully integrated a pure 3D Cadastral system on a national scale, although the developments towards this direction are rapid. GIS tools incorporate new more sophisticated 3D features; DBMS are 
being further developed in order to fully support 3D registration and industry is focusing more and more on the third dimension. Nevertheless the implementation of a 3D cadastral model and the generation, manipulation and dynamic updating of 3D information requires the balanced collaboration of cadastral, legal and technical factors which is a quite challenging task.

\subsection{Cases requiring 3D registration}

There are multiple examples of RRRs and spatial units requiring 3D registration (Dimopoulou and Elia, 2012) such as: - Airspace rights, a relatively new type of development rights that refer to the $3 \mathrm{D}$ space above a property, which can be reasonably used or occupied. Airspace ownership has to be legally limited and 3D displayed, not to interfere with air travels, as derived by the aviation law.

- The "building-within-a-building", a new concept in the commercial office market (of New York) that recaptures and exploits spaces in office towers that were not fully used, in order to accommodate different tenancies benefiting separate entrance and minimizing costs.

- Rights to exploit mines and produce minerals lying below the surface of the property, depending on each jurisdiction.

- Littoral and riparian water rights in front of properties, according to relative national legislation.

- Special constructions above or below freeways, railroad tracks, such as bridges, tunnels etc.

- Telecommunication and electric conduits and utilities on land ownership.

- Rights that comply with zoning and planning regulations for urban growth, management and protection of environment and cultural heritage.

- Multi-level property resulting from a building that is partly constructed on or in another's land. Based on the rule of "horizontal accession to real estate", the result of the construction over the parcels boundary is horizontal division of ownership (Stoter et al., 2012).

As well as some characteristic cases within the Greek territory: - Overlapping private properties; in many Greek Islands properties are partially or totally overlapping each other due to intense relief. According to Dimopoulou et al (2006) these property rights are mainly based on customary laws.

- Special Real Property Objects as mentioned below (see 2.2).

\section{HELLENIC CADASTRE}

The Hellenic Cadastre (HC) collects information on property objects, which is in reference with the land-parcel and is analyzed on the two dimensions of the real objects. The $\mathrm{HC}$ is in fact a two-dimensional registration system, while other objects such as 3D space units (e.g. apartment rights) are manipulated within a limited context. Until lately 2D Cadastral systems were moderately sufficient and adequate in most conventional situations worldwide. However, according to Zentelis (2011) this type of registration system can no longer portray the contemporary and evolving more complexstructured environment satisfactorily, in which cases of development and multiple use of space, as well as the layered distribution of rights is prevalent.

\subsection{Cadastral Database}

Conceptual model: The Hellenic Cadastral model is organized on the basic relation scheme e.g. person - right - real estate object. In addition, appurtenances accompany real estate objects, while deeds generating or proving the right accompany the right itself.

The conceptual model of the two dimensional cadastral model is organized in reference with the land parcel (parcel-based), which additionally contains rights applying on the parcel. The conceptual data model of the HC project was designed using Entity Relationship (ER) diagram, which separates the object of interest in entities.

Logical model: During the logical design, the conceptual model is translated into the logical model and, in particular, into a data model of a specific DBMS type (Stoter and van Oosterom, 2006). The Hellenic Cadastre uses relational DBMS Oracle $10 \mathrm{~g}$, thus the logical model is basically relational concerning the actual database, although it contains additional object-oriented applications.

\subsection{D Information within the Greek Cadastral Model}

The Greek cadastral model includes (Tsiliakou and Dimopoulou 2011):

Buildings: Although the spatial database contains the information of buildings, it is not actually represented on the cadastral maps. However, 3D features in the case of horizontal ownership, are only registered as attribute or are descriptively provided.

S.R.P.O.s: Special Real Property Objects concern a plethora of objects ("Anogeia", "Yposkafa", Mines, Arcades, Tanks, Arches, Windmills etc), which are characterized by multiple and complex topological relations applying between various properties and are the only 3Ds managed in the existing cadastral model. They are mostly manipulated not as spatial information but as descriptive via a relational / topological matrix, which includes the description of these objects in a structured descriptive manner using definitions such as "above" or "below". The S.R.P.O.s can be identified in the cadastral system as:

- Polygons in a different thematic layer than the parcels accompanied by the topological matrix;

- Points which correspond to the entries of S.R.P.O.s with no percentage of ownership on the land-parcel (e.g. anogeia or katogeia) accompanied by the topological matrix.

- Descriptive information merely defined by the topological matrix. In particular, they are described with a 12-digit cadastral number assigned by the $\mathrm{HC}$, accompanied by a special comment, indicating the cadastral numbers of the other parcels, with which they involve.

\section{3. nD GEOINFORMATION}

Manipulation and analysis of contemporary cadastral data constitute a demanding process considering all the parameters needed to be taken into account such as cultural, legal, economic, social and environmental factors. After all, cities are dynamic living organisms that are evolving through interplay of regulatory and entrepreneurial activities (Hamilton et al, 2005). Geographical information is undoubtedly the core of land management systems or Cadastres, although this information must be combined and integrated within the cadastral system with multiple attributes like history, culture, economy, society, environmental factors, technical developments as well as the temporal dimension. Collecting and storing those data is a standard process, through managing and analyzing them within an integrated platform can be a challenging and tricky task. The larger the set of possible operations is, the more complex data 
analysis can be performed (Zlatanova, 2002). Temporal dimension is a major issue, the "architect" of data management, decision making and urban planning since experiences from the past (remote or near) constitute paradigms and practices or possible scenarios for future planning.

GeoInformation models improve considerably the effectiveness of cadastral systems and the analysis process, while providing a more comprehensive image of reality. They are information framework or infrastructure for data integration and interoperability, employing the emerging data management technologies like database, XML and including standards, metadata, ontology and data services (Hamilton et al., 2005).

Models are the apparatus, translating the real world into a digital substance, providing their own interpretation of the contemporary data according to the users and the purposefulness of the system. A data model provides system developers and users with a common understanding and reference point (Longley, 2001). A complete model consists of spatial objects as well as non-spatial attributes integrated within a system, supplying the users with a conceptual analysis of the data and explanation of real phenomena. Spatial objects are represented by their geometric and semantic characteristics and spatial relationships (Zlatanova, 2002).

Spatial objects can optimally be analyzed and manipulated in accordance to their third dimension, not just as planar entities. Besides, the contemporary and evolving more complexstructured environment can be satisfactorily comprehended through $3 \mathrm{D}$ visualization and management.

3D spatial objects can be modeled using various 3D primitives (Scianna and Ammoscato, 2010):

- CAD and 3D computer graphics' objects: solids can be modeled by wireframe (points, line and curves), by surfaces (using surfaces with no thickness) or by solids (using Constructive Solid Geometry or Boundary Representation);

- Tetrahedron (Stoter and Van Oosterom, 2002): it consists of four triangles that form a closed object in 3D coordinate space;

- Polyhedron (Stoter and Van Oosterom, 2002): it is like a polygon, but in $3 \mathrm{D}$. It is constituted by several flat faces that enclose a volume.

Fortunately, land management systems have been enriched with IT tools, thus improving the whole process of data capturing and analysis. Most importantly various current software aim at the manipulation of 3D geo-information and the management of 3D models, though still at developing context due to the difficulties when collecting and processing data originated from the $3 \mathrm{D}$ complex-structured environments. GIS software as a sophisticated IT application deals effectively with spatial information since it is capable of connecting with DBMS which stores this information, manages both spatial and non-spatial attributes of objects, reveals spatial relationships and performs spatial analysis. Promising plans for the near future are to build complete 3D virtual environments, interactive as well as smart 3D models supporting spatial and temporal dimensions, although this process is complex and would require substantial improvements in 3D software.

\section{3D MODELING SOFTWARE}

It is evident that the use of three-dimensional features has considerably increased during the last decade in various computer based fields such as gaming, animation, GIS, cadastral systems, decision making etc. Regarding cadastral systems, the definition of a multilayer and three-dimensional cadastral model will enable the reflection of the allocation of rights and ownership status within the actual 3D reality; generally, though the third dimension helps to better analyze a situation or a model: it is essential in every advanced geographical information system or everywhere correct 3D position is important (Scianna and Ammoscato, 2010). The need for 3D modeling triggered further sophistication of software and ever since new or old packages (proprietary, opensource or free) are available, improved with more refined 3D features. One of the most beneficial aspects of these packages is their interaction and interoperability with other applications and files.

Nonetheless, two are the main concerns related to cadastral systems and the corresponding software: is the software suitable for building realistic and accurate $3 \mathrm{D}$ models with actual metric information? How do they interact with spatial databases maintaining large amounts of geographical and cadastral datasets?

Some of the most prevalent proprietary, open-source and free software packages containing 3D features, can be seen below. Most of them interact with different Operating Systems (such as Windows, Macintosh, Linux, Win32), as well as with other software.

- Proprietary packages: 3ds Max (Autodesk), Aladdin4D (DiscreetFX), LightWave 3D (NewTek), MASSIVE I, Maya (Autodesk), Realsoft3D Real3D, Remo 3D I, Cheetah3D, CityEngine (Procedural Inc), NX (Siemens PLM Software), form $\cdot Z$ (AutoDesSys, Inc.), Grome, Inventor (Autodesk), Rhinoceros 3D, SketchUp Pro (Trimble), Swift 3D (Electric Rain), solidThinking (solidThinking) and many more;

- Open source packages: Blender (Blender Foundation), CloudCompare, Seamless3d, Wings 3D, FreeCAD;

- Free software packages: AutoQ3D Community, K-3D, MeshLab, OpenFX, KernelCAD, Art of Illusion;

$3 \mathrm{D}$ representation of buildings, as well as other infrastructure and DTM features is currently evolving through CityGML, an open standard data model based on Geography Markup Language 3 and supported by the Open Geospatial Consortium (OGC). CityGML can fully describe 3D objects in terms of geometry, topology, semantics and appearance through five levels of detail (LoD), aiming to reach a common definition of the basic entities, attributes, and relations of a 3D city model.

INSPIRE Directive's Data Specification on Buildings, refers to a data model that allows multiple representations of buildings and constructions, through a set of four profiles with different levels of detail both in geometry and semantics. The 2D surface representation is the most frequent, while the 3D representations of buildings are generally described through the CityGML OGC standard.

\section{3D GIS}

3D GIS include capabilities for the creation of highly detailed 3D models using 2D GIS data. CityEngine is such a tool, being a three-dimensional modeling software, specializing in the generation of 3D urban environments and the creation of complex parametric models from 2D datasets. This application employs procedural modeling, proving its capability to generate models via a predefined set of rules. The creation of $3 \mathrm{D}$ models is triggered via a CGA shape grammar system that controls the rules set, while the user himself can customize the shape grammar in order to practice with new design options. The software has been used broadly towards the making of detailed 3D models of virtual cities both for urban planning purposes or animation; thus its possibilities of modeling the reality of contemporary urban landscapes are quite promising. After all, approaches such as procedural modeling with shape grammars have many advantages such as automatic generation, great flexibility for variation, object hierarchy, scalable geometric 
representation and data handling of large models (Dore and Murphy, 2013).

\subsection{CityEngine Workflow}

City engine is a user friendly software allowing both computer and non-computer scientists to create and interact with complex 3D models from scratch, through a specific workflow. Building the model usually starts with the creation of street networks with the "grow streets" tool or through maps imported either from openstreetmaps.org or geodatabases. Completing street networks, blocks are being formed, which further get subdivided into lots and following, the detection of the buildings' footprints takes place. This can be achieved by importing shapefiles, or CAD-drawings or openstreetmaps data signifying those footprints accompanied by height values.

Completing this workflow, we will have built a new city or any typical urban environment enclosing basic features such as streets, blocks etc., although at this stage of the process this is merely geographical information visualized in 2D. In order to utilize the third dimension and extract the buildings' volume, an extrusion rule must be applied. The shape grammar can always be modified according to our needs or some of the parameters can be manually adjusted resulting in the urban model's redesign and improvement. One of the most interesting modifications applied is setting different Levels of Detail (LOD), which facilitate the visualization of buildings with a minor significance in a lower level of detail, differentiating them from buildings with great significance for the purpose of our model. The big advantage of CityEngine for planning practice is the option of interrupting this process at any time allowing for manual correction outside of the software (Schirmer and Kawagishi, 2009).

\subsection{Shape Grammar}

A basic tool of CityEngine is its python scripting language CGA (Computer Generated Architecture). Shape grammars, originally defined by George Stiny and James Gips in 1971; contain a set of production rules (such as shape rules) and a generation engine that enables the procedural generation of $3 \mathrm{D}$ geometric shapes, considering an initial 2D geometry. The philosophy of procedural modeling is, instead of designing content by hand, to design a procedure that creates content automatically (Smelik et al., 2009). Shape rules vary from a start rule which triggers the generation of the whole process, transformation rules and a termination rule which obviously terminates the process. At last, the desired 3D model is being created in a predefined working space.

One of the most applicable CityEngine tools that use shape grammar is Façade Wizard. This wizard generates façades according to Müller et al (2007), who propose a well-structured smart method combining images and shape grammar creation, easy to apply and work with. The input data is a single rectified image (functioning as texture) of a specific building and the output data is a highly detailed 3D model enclosing all the façade's features such as doors, tiles, ledges etc. This method recognizes the façade structure via symmetry recognition with help of the user's perspective. In addition the user also defines the depth for façade regions created manually in respect to his visual perception. Façade Wizard splits the volumes into their sides at first, and then it further divides each side into floors and tiles. According to Dore and Murphy (2013) further tile refinement is automatically carried out using edge detection to split tiles into smaller regions (window positions, ledges and window sills) using a subdivision concept from procedural modeling which creates a hierarchy of elements and finally the computed façade can be exported as shape grammar rules in the CGA editor. Applying the new rule file to the desired shape and hitting the "generate" button results in a detailed volume consisting of façade structures within a few seconds. Various alterations on the façade can then be performed, in order to further refine it by experimenting with given parameters such as number of stories, depth or repetition of windows, walls' thickness etc.

It is evident to both computer and non-computer scientists, that using shape grammar minimizes the effort of the whole -2D data transformation into $3 \mathrm{D}$ - modeling process and maximizes the quality of the final 3D product.

\section{CASE STUDY}

The transition of 2D source data into a 3D model was applied to the National Technical University of Athens (NTUA) campus area, which consists of eight academic departments, accommodation, administration and other facilities. Concerning its ownership status, the NTUA campus comprises four distinct cadastral parcels which are relatively registered in 2D within the Greek cadastral model and assigned different cadastral numbers. The first parcel (under the 050531601001 cadastral number) is the initial parcel with the larger area, while the other three (under 050531601002, 05053161008 and 05053161009 cadastral numbers respectively) are smaller parcels which were later added to the initial parcel (as shown in figure 1).

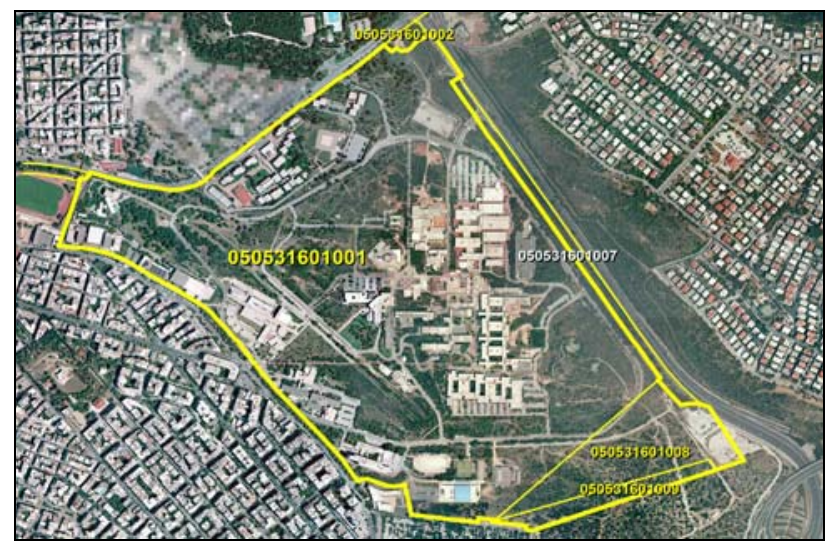

Figure 1. NTUA's distinct cadastral parcels

The ownership status of the campus area is rather complex, as a result of claims, land disputes and trespasses. More specifically, part of the disputed area was exchangeable land between the NTUA and the neighbouring military services. The trespassed area mainly comprises State facilities (such as a primary school, a cemetery, an accommodation facility and constructions of the University of Athens) that have been illegally erected on an encroached part of the campus area. Concerning the construction activity of the campus, although most buildings have a building permit, some were initially illegally constructed and legalized afterwards. The NTUA's Master Plan is an extension of the urban plan under special regulation (Government Gazette 979D/7-9-1981), specifying that buildings and other facilities and constructions have to respect building regulations such as coefficient coverage $15 \%$ and building coefficient 0.45 for the whole campus. Further regulations concern the maximum number of stories, in 12 floors (currently with a maximum number of 10 floors in students' residencies), as well as the maximum buildings' height which is 40 meters. Since the aim of this paper is to 
represent the cadastral situation, including constructions within the university campus via 3D modeling, at this point, we focus our efforts to optimally visualize them through shape grammar rules in order to transform it into realistic 3D shapes lying on the campus actual terrain. Those shapes can be treated as 3D right-objects, revealing the insight on the vertical component of each construction's rights.

\subsection{Datasets}

The campus' 3D model was built by using different parameters based on input data derived from cadastral and urban planning datasets, as well as legal documents and architectural plans. Specifically the Technical Services of NTUA provided us with a number of datasets (in CAD files), a topographical map of the campus area, geo-referenced in the Hellenic Geodetic Reference System, architectural plans of the existing and future buildings also geo-referenced, as well as, floor plans, views and sections of the School of Rural and Surveying Engineering (SRSE) (consisting of Lampadarios and Veis buildings, built in different time periods). For the entire campus area, a pivot table was also provided with information on the number of floors, the constructions' materials, the date of construction, and finally a cadastral diagram also geo-referenced with related legal documents that describe the ownership status. The Hellenic Mapping and Cadastral Organization (HEMCO) provided us with the necessary orthophotos (VLSOs) and the D.E.M. which both served as a basis to our modeling approach.

\subsection{Methodological Approach}

First a workspace in CityEngine has been defined in order to be able to organize our data and optimally process them into a 3D model. The creation of a geodatabase in ArcCatalog including the desired features with attributes follows the data organization in assets, data, models, images, maps, rules, scenes and scripts. Among the above, the rules file includes the entire shape grammar rule set necessary for the generation of the final model.

At first, the terrain is usually formed by importing the available DTM and a georeferenced texture file which is the corresponding orthophoto. In our case the DEM provided was converted to DTM by excluding the constructions' height values, securing that way that the final terrain model would refer to the actual ground. Once the terrain was created the next step concerned the constructions' modeling. This can be achieved either by importing data a) from openstreetmaps.org, or/and b) as a geodatabase (.gdb). Having experimented with both approaches the second one was chosen, because the constructions' footprints derived from the campus 'topographical plans in national reference grid; thus it was undoubtedly the most efficient approach in matters of precision, since the official coordinates of the buildings' footprints were provided. After importing the buildings' footprints, the $3 \mathrm{D}$ shape generation is done by applying simple rules, which we downloaded from City Engine's resources center, to selected buildings' footprints. A simple extrusion rule has been used which obviously extrudes the footprints' volume and a rule containing façade texture in order to give a more realistic volumetric impression on some of the campus' constructions. Once those rules were assigned, the buildings' heights were set according to the height information originated from both the $\mathrm{CAD}$ files and the pivot table and finally those $3 \mathrm{D}$ shapes were generated and aligned to terrain. This was quite a challenging process, in terms of validated 3D geometry and 3D topology. Although most shapes were strictly aligned to the terrain, a more thorough approach results in a more well-structured 3D model; thus the constructions' height information has been combined with the terrain's altitude information from the available CAD files (which included contours and $\mathrm{z}$ values) in order to optimally assign the $3 \mathrm{D}$ shape on the corresponding image on the terrain, in cases where the relief was more intense. Some first results concerning the $3 \mathrm{D}$ representation of the entire campus can be seen in figure 2. Regarding the visualization of SRSE premises, an upper level of precision was applied in order to provide a more realistic impression of the buildings' volume.

For this purpose the facades' textures were collected as well as various other textures such as the roofs' textures, windows etc; these textures, which were simply applied on the 3D objects' facades or sides via drag and drop, portray a realistic image of the SRSE (Figure 3).

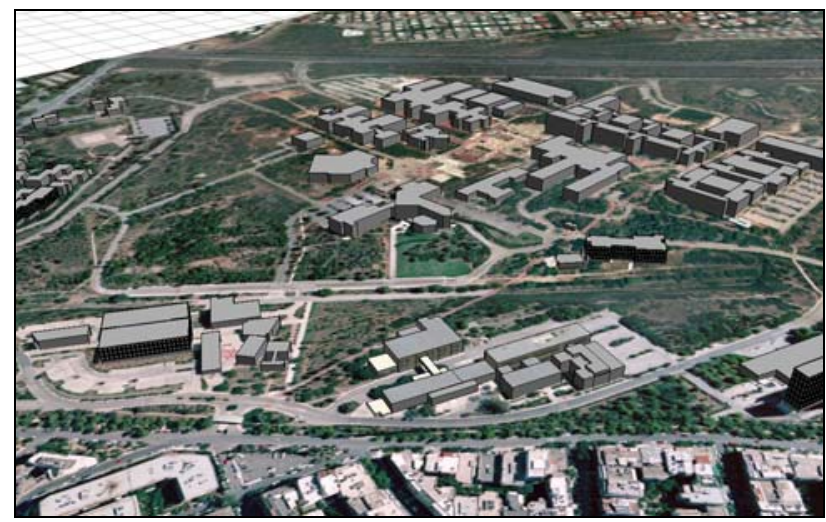

Figure 2. Perspective general view of NTUA Campus

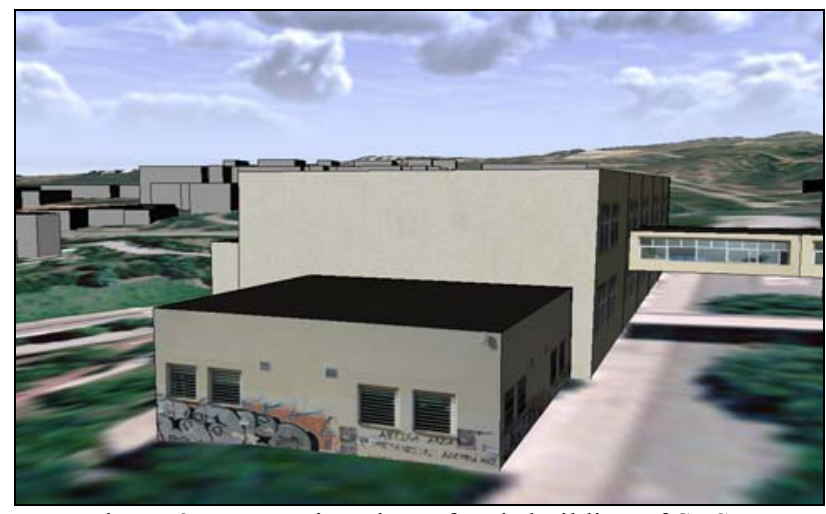

Figure 3. Perspective view of Veis building of SRSE

For the design of the Lampadarios building, a new shape grammar rule was created in order to provide a higher level of detail on the building's final volume. The shape grammar rules consist of all the rules necessary to perform the partition of the 3D object into floors, tiles, doors, windows and pillars (Figure 4 ), as well as all the available textures that complete the model's realistic impression (Figure 5).

The model would meet the $\mathrm{nD}$ Geo-information principles if a temporal dimension was also applied. Concerning the NTUA campus this can be achieved with a dynamic monitoring of new buildings and other constructions' extensions and by periodically detecting campus land use or ownership status changes that may occur through time.

\section{CONCLUSIONS}


It is quite evident that promising results can be achieved by utilizing 3D modeling software for the manipulation and visualization of geographical data as well as for cadastral purposes, where simple 3D visualisation fulfils many current users. The continuous development of information technology such as GIS and the integration of temporal dimension expand the possibilities of geo-management in spatial analysis, not only on a $2 \mathrm{D}$ level but also on 3D.

Procedural modeling and experiences from practicing shape grammars indicate their effectiveness at numerous scales of $3 \mathrm{D}$ design and visualization of $3 \mathrm{D}$ geometries. After all, procedural modeling techniques, which are more easy to use, are becoming progressively more attractive to various real-world applications, in contrast to the time consuming and obsolete manual reconstruction and correction of models.

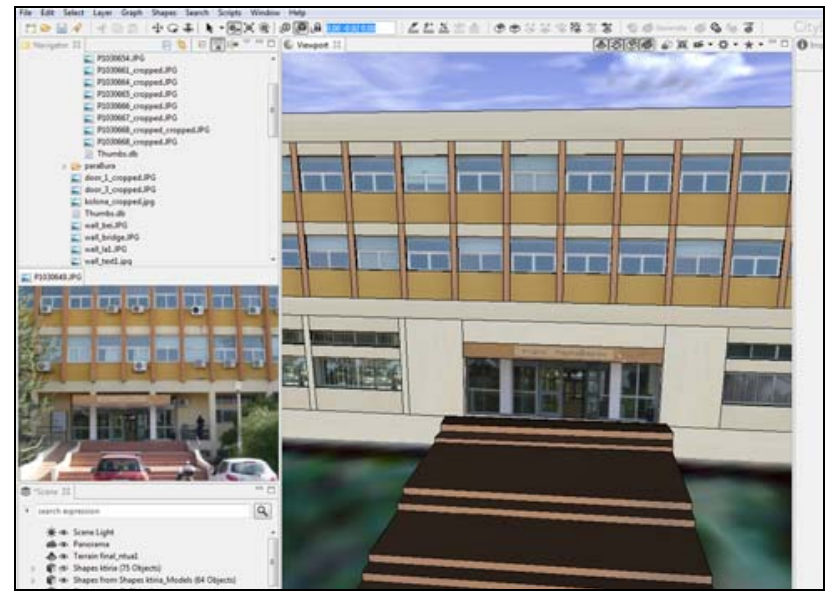

Figure 4. Lampadarios building generated with CGA rules

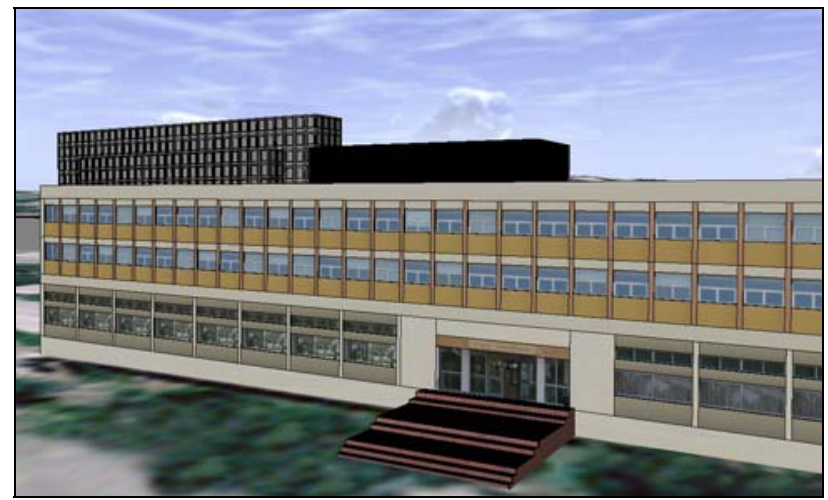

Figure 5. Perspective view of Lampadarios building

3D GIS software such as the one used in this project are undoubtedly powerful software packages for the generation of accurate and realistic 3D models, transforming $2 \mathrm{D}$ data into dynamic 3D representation and providing an efficient tool for $3 \mathrm{D}$ zoning validation. Future trends adopt the idea of integrating GIS, CAD and DBMS in a unified platform, which would considerably benefit needs in 3D Cadastral Systems worldwide.

This research work is still in progress moving towards the development of systematic and automated procedural processes.

\section{REFERENCES}

Aien, A., Kalantari, M., Rajabifard, A., Williamson, I., Bennett, R., 2011, Advanced principles of 3D cadastral data modeling, Proceedings of the 2nd International Workshop on $3 D$
Cadastres, November 16-18, 2011, Delft, The Netherlands, pp.377-396

Bennett, R. et al (2008). A toolbox for mapping and managing new interests over land. Survey Review, 40(307), 43-53.

Dimopoulou, E., Elia, E., 2012, Legal Aspects of 3D Property Rights, Restrictions and Responsibilities in Greece and Cyprus, Proceedings of the 3rd International Workshop on $3 D$ Cadastres: Developments and Practices, October 25-26, 2012, Shenzhen, China

Dimopoulou, E., Gavanas, I., Zentelis, P., 2006, 3D Registrations in the Hellenic Cadastre. Proceedings of the XXIII FIG Congress: Shaping the Change, October 8-13, 2006, Munich, Germany

Dore C., Murphy M., 2013, Semi-automatic modelling of building façades with shape grammars using historic building information modeling, International Archives of the Photogrammetry, Remote Sensing and Spatial Information Sciences, Volume XL-5/W1, 20133D-ARCH 2013 - 3D Virtual Reconstruction and Visualization of Complex Architectures, February 25-26, 2013, Trento, Italy

Hamilton, A, Wang, H, Tanyer, AM, Arayici, Y, Zhang, X, Song, YH, 2005, Urban information model for city planning, Journal of Information Technology in Construction (ITCon), pp.55-67

Jantien Stoter J., van Oosterom P., Ploeger H., 2012, The phased 3D Cadastre implementation in the Netherlands, 3rd International Workshop on 3D Cadastres: Developments and Practices, October 25-26, 2012, Shenzhen, China

Kalantari, M. et al (2008). Spatially referenced legal property objects. Land Use Policy, 25, 173-183.

Müller, P., Zeng, G., Wonka, P., Gool, L.V., 2007, Image-based Procedural Modeling of Facades, ACM. Transactions on Graphics, Vol.26, No.3, pp. 85, July 2007

Schirmer, P., Kawagishi, N., 2011, Using shape grammars as a rule based approach in urban planning - a report on practice, 29th eCAADe Conference Proceedings, ISBN 978-9-49120701-3, September 21-24, 2011, Ljubljana, Slovenia, pp.116-124 Scianna A., Ammoscato, A., 2010, 3D GIS Modeling using open source software, ISPRS Archive Vol. XXXVIII, Part 4-82-W9, Core Spatial Databases - Updating, Maintenance and Services - from Theory to Practice", Haifa, Israel, 2010

Smelik, R.M., Kraker, K.J., Groenewegen, S.A., Tutenel, T., Bidarra R., 2009, A Survey of Procedural Methods for Terrain Modelling, Proceedings of the CASA Workshop on $3 D$ Advanced Media In Gaming And Simulation (3AMIGAS), Amsterdam, The Netherlands, 2009

Stoter, J.E., 2002, UML Modelling: From a 2D to a 3D Cadastre, Proceedings of the 3rd international workshop: Towards a Cadastral Core Domain Model of COST action G9: Modelling Real Property Transactions, October 10-12, 2002, Delft, The Netherlands

Stoter, J.E., van Oosterom, P.J.M., 2006, 3D Cadastre in an international context: legal, organizational and technological aspects, Taylor \& Francis, CRC, 2006. ISBN: 0-8493-3932-4.

Tsiliakou, E., Dimopoulou, E., 2011. Adjusting the 2D Hellenic Cadastre to the Complex 3D World - Possibilities and Constraints, Proceedings of the 2nd International Workshop on 3D Cadastres, November 16-18, 2011, Delft, The Netherlands, pp.115-35

van Oosterom, P.J.M., Stoter, J.E., Ploeger, H.D., Thompson, R.J., Karki, B.S., 2011, World-wide inventory of the status of 3D Cadastres in 2010 and expectations for 2014, FIG Working Week 2011: Bridging the Gap between Cultures, May 18-22, 2011, Marrakech, Morocco

Zentelis, P., 2011, About Land and Cadastre (in Greek), Papasotiriou, ISBN: 978-960-491-014-4. 
International Archives of the Photogrammetry, Remote Sensing and Spatial Information Sciences, Volume XL-2/W2, ISPRS 8th 3DGeolnfo Conference \& WG II/2 Workshop, 27 - 29 November 2013, Istanbul, Turkey

Zlatanova, S., 2002, The future of 3D geo-information, Jubilee scientific conference on the occasion of the 60th anniversary of the University of Architecture Civil Engineering and Geodesy, Vol. 8, Geodesy, Transportation Engineering, Geotechniques, Mathematics and Physics, November 20-23, Sofia, Bulgaria, pp. $31-41$ 